\title{
Does choice of anesthetics affect intraoperative blood loss?
}

\author{
Seonghoon Ko \\ Department of Anesthesiology and Pain Medicine, Chonbuk National University Medical School and Hospital, Jeonju, Korea
}

Over the last 10 years, endoscopic surgical techniques have been developed rapidly and are widely used in the most surgical areas for the minimal invasive surgery. In many endoscopic operations, even a small amount of bleeding can interfere with the optimal visualization of the surgical field because of the limitation of the surgical space and the magnification of the vision. Increased bleeding results in further difficulties in obtaining the optimal surgical field, which not only the operation becomes more difficult and takes more time but also increases the risk of complications. Thus, various attempts have been used to obtain a relatively bloodless surgical field during endoscopic surgery in order to get optimal visualization, including controlled hypotensive anesthesia.

In this issue of Korean Journal of Anesthesiology, Cho et al. [1] compared surgical field conditions, which were assessed by the amount of bleeding of the operating site between propofol/remifentanil anesthesia and desflurane/remifentanil anesthesia in patients undergoing endoscopic sinus surgery. They demonstrated that propofol/remifentanil anesthesia results in better surgical field conditions for endoscopic sinus surgery than desflurane/remifentanil based anesthesia. Several contradictory studies on this subject have been reported. Some studies showed propofol-based anesthesia had better surgical field and less amount of bleeding than inhalational anesthesia [2-6], but other studies did not show any differences $[7,8]$. Although the concept that anesthesia may contribute to blood loss during surgery is not new, anesthesiologists need to keep in mind that anesthetics can affect surgical bleeding.

For the relatively bloodless surgical field during endoscopic sinus surgery, various methods have been adopted, such as an epinephrine infiltration, reverse Trendelenburg position, or controlled hypotension. Traditionally, controlled hypotension has been used to reduce the amount of blood loss and provide the dry surgical field in many surgical areas, but it can cause some problems such as rebound hypertension, reflex tachycardia, and organ ischemia. Furthermore, several studies demonstrated that the amount of intraoperative blood loss and a dry surgical field are not necessarily related to blood pressure during controlled hypotension with cardiovascular drugs $[9,10]$. Because the modern inhalational anesthetics and propofol cause concentration-related decreases in arterial pressure, controlled hypotension can be achieved by anesthetics without cardiovascular drugs. If an anesthetic decreases the amount of blood loss during surgery, this is to a great extent a merit of the anesthetic because controlled hypotension with cardiovascular drugs is limited in this case.

In general, the amount of surgical blood loss is related to perfusion pressure and peripheral vasodilation of the surgical site, as well as to injured blood vessels and coagulation status. Because most anesthetics have vasodilatory effects in spite of the slightly different effects among the anesthetics, choice of anesthetics may also have an effect on surgical bleeding. The vasodilating effect of the anesthetics can induce hypotension, which may decrease bleeding, but the effect may cause a capillary bleeding despite systolic blood pressure being low. Although propofol and inhalational anesthetics have a similar vasodilatory effect, the effects on heart rate are different. Isoflurane and desflurane show apparent reflex tachycardia, but sevoflurane usually does not alter the heart rate [11]. In contrast, propofol decreases heart rate by inhibition of the baroreflex [12]; thus propofol suppresses the cardiac output more than modern inhalational anesthetics. Therefore, the lower intraoperative

Corresponding author: Seonghoon Ko, M.D., Ph.D., Department of Anesthesiology and Pain Medicine, Chonbuk National University Medical School and Hospital, 634-18, Keumam-dong, Jeonju 561-712, Korea. Tel: 82-63-250-1979, Fax: 82-63-250-1240, E-mail: shko@jbnu.ac.kr (c) This is an open-access article distributed under the terms of the Creative Commons Attribution Non-Commercial License (http:// creativecommons.org/licenses/by-nc/3.0/), which permits unrestricted non-commercial use, distribution, and reproduction in any medium, provided the original work is properly cited. 
heart rate in patients underwent endoscopic sinus surgery with propofol anesthesia has a postulated mechanism of reduced intraoperative bleeding $[3,6]$. In addition, propofol decreases cerebral blood flow in parallel with depression of the cerebral metabolic rate [13]. Decreased cerebral blood flow with propofol would be expected to reduce blood flow to the ethmoid, sphenoid, and frontal sinuses and this would be the other potential mechanism to reduce bleeding.

Although the mechanisms are not clearly elucidated as yet and furthermore it is unclear whether propofol-based anesthesia actually reduced the amount of bleeding compared with the inhalational anesthesia, the results of many prospective studies showed improvement in surgical grade for endoscopic sinus surgery in the propofol-based anesthesia compared to inhalational anesthesia. Most studies show that anesthetics affected the intraoperative bleeding and surgical field conditions are limited to the specific type of surgery including endoscopic sinus surgery. However, these effects of anesthetics are not thought to be limited to a few types of surgeries. These effects may be shown in all kind of surgery. The anesthesiologists did not aware that how the operation procedure is affected by the amount of blood loss during operation other than endoscopic sinus surgery. This may be a reason of the lack of the studies on the other type of surgery. Because the modern anesthetics do not induce serious anesthetic-related complications, the choice of the anesthetics should be considered by the safety of the patients and surgical conditions, such as intraoperative bleeding as well. Therefore, anesthesiologists have to investigate whether propofol actually reduced the amount of bleeding compared with the inhalational anesthesia in most surgeries and look forward to see the results.

\section{References}

1. Cho KR, Lee JY, Park SK, Cheong SH, Lee KM, Lim SH, et al. Comparison of surgical conditions during propofol or desflurane anesthesia for endoscopic sinus surgery. Korean J Anesthesiol 2012; 63: 302-7.
2. Pavlin JD, Colley PS, Weymuller EA Jr, Van Norman G, Gunn HC, Koerschgen ME. Propofol versus isoflurane for endoscopic sinus surgery. Am J Otolaryngol 1999; 20: 96-101.

3. Eberhart LH, Folz BJ, Wulf H, Geldner G. Intravenous anesthesia provides optimal surgical conditions during microscopic and endoscopic sinus surgery. Laryngoscope 2003; 113: 1369-73.

4. Manola M, De Luca E, Moscillo L, Mastella A. Using remifentanil and sufentanil in functional endoscopic sinus surgery to improve surgical conditions. ORL J Otorhinolaryngol Relat Spec 2005; 67: 836.

5. Wormald PJ, van Renen G, Perks J, Jones JA, Langton-Hewer CD. The effect of the total intravenous anesthesia compared with inhalational anesthesia on the surgical field during endoscopic sinus surgery. Am J Rhinol 2005; 19: 514-20.

6. Ahn HJ, Chung SK, Dhong HJ, Kim HY, Ahn JH, Lee SM, et al. Comparison of surgical conditions during propofol or sevoflurane anaesthesia for endoscopic sinus surgery. Br J Anaesth 2008; 100: 50-4.

7. Yoo HS, Han JH, Park SW, Kim KS. Comparison of surgical condition in endoscopic sinus surgery using remifentanil combined with propofol, sevoflurane, or desflurane. Korean J Anesthesiol 2010; 59: 377-82.

8. Beule AG, Wilhelmi F, Kuhnel TS, Hansen E, Lackner KJ, Hosemann W. Propofol versus sevoflurane: bleeding in endoscopic sinus surgery. Otolaryngol Head Neck Surg 2007; 136: 45-50.

9. Boezaart AP, van der Merwe J, Coetzee A. Comparison of sodium nitroprusside- and esmolol-induced controlled hypotension for functional endoscopic sinus surgery. Can J Anaesth 1995; 42: 373-6.

10. Jacobi KE, Bohm BE, Rickauer AJ, Jacobi C, Hemmerling TM. Moderate controlled hypotension with sodium nitroprusside does not improve surgical conditions or decrease blood loss in endoscopic sinus surgery. J Clin Anesth 2000; 12: 202-7.

11. Pagel PF, Farber NE, Pratt PF Jr, Warltier DC. Cardiovascular pharmacology. In: Miller R. Miller's anesthesia. 7th ed. Philadelphia, Churchill Livingstone. 2010, p 602.

12. Reves JG, Glass PSA, Lubarsky DA, McEvoy MD. Martinez-Ruiz R. Intravenous anesthetics. In: Miller R. Miller's anesthesia. 7th ed. Philadelphia, Churchill Livingstone. 2010, pp 724-6.

13. Haberer JP, Audibert G, Saunier CG, Muller C, Laxenaire MC, Hartemann D. Effect of propofol and thiopentone on regional blood flow in brain and peripheral tissues during normoxia and hypoxia in the dog. Clin Physiol 1993; 13: 197-207. 